Н. А. Зеничев

Российская правовая акаделия

Министерства юстиции Российской Федерации, г. Москва, Российская Федерация

\author{
ИСПОЛЬЗОВАНИЕ НЕЗАКОННЫХ ТАКТИК ВЗЫСКАНИЯ \\ ДЕНЕЖНЫХ СРЕДСТВ КОЛЛЕКТОРСКИМИ АГЕНТСТВАМИ \\ И МЕТОДЫ БОРЬБЫ С НИМИ \\ В СТРАНАХ АНГЛО-САКСОНСКОЙ ПРАВОВОЙ СЕМЬИ
}

\begin{abstract}
АНнотАЦия. Статья посвящена исследованию зарубежного опыта борьбы со злоупотреблениями в ходе взыскания денежных средств представителями коллекторских агентств. Описывается законодательство стран англо-саксонской правовой семьи, имеющих наиболее обширную практику правоприменения в данной области. Рассматриваются особенности запретов и ограничений, закрепленных в американском Законе о добросовестной практике взыскания долгов (1977), принятом с целью максимально подробно урегулировать деятельность в данной сфере. Исследуются судебные и внесудебные способы защиты нарушенных прав должника, полномочия органов, занимающихся защитой прав должников. Производится анализ влияния степени регулирования рынка коллекторских услуг и экономических факторов на количество и серьезность нарушений прав должников. В заключение делаются выводы о влиянии природы и модели коллекторской деятельности на количество злоупотреблений со стороны коллекторов.

КЛЮчЕВЫЕ СЛОВА. Коллекторы; тактики взыскания; Закон о добросовестной практике взыскания долгов; злоупотребление; англо-саксонская правовая семья.

ИНФОРМАЦИЯ О СТАТЬЕ. Дата поступления 10 апреля 2015 г.; дата принятия к печати 25 декабря 2015 г.; дата онлайн-размещения 29 января 2016 г.
\end{abstract}

N. A. Zenichev

Russian Law Academy of Ministry of Justice of Russian Federation, Moscow, Russian Federation

\title{
USE OF ILLEGAL TACTICS OF COLLECTING MONETARY ITEMS BY COLLECTION AGENCIES AND METHODS OF COMBATTING THEM IN THE COUNTRIES OF ANGLO-SAXON LEGAL FAMILIES
}

\begin{abstract}
The article is devoted to investigating foreign experience of combatting abusive practice in collecting monetary items by collection agencies. It describes legislations of the countries of Anglo-Saxon legal family that have the most extensive practice of law enforcement in this area. It considers the features of the bans and restrictions enshrined in the US 1977 Fair Debt Collection Practices Act (1977), which was adopted with the aim to regulate in detail the activities in this sphere. It investigates judicial and non-judicial methods of protecting debtors' violated rights, powers of the bodies involved in protecting debtors' rights. It analyzes the impact of the degree of regulating the collection services market and economic factors on the number and severity of violating debtors' rights. In the end, a conclusion is made about the influence of nature and models of collection activities on the number of abuses on the part of the collectors. KEYWORDS. Collectors; collection tactics; Fair Debt Collection Practices Act; abuse; Anglo-Saxon legal family. ARTICLE INFO. Received April 10, 2015; accepted December 25, 2015; available online January 29, 2015.
\end{abstract}

\section{Baikal Research Journal}


Как следует из статистики, опубликованной Центральным банком РФ, просроченная задолженность по кредитам физических лиц за 2014 г. выросла на 51,9\% до 667,3 млрд р. ${ }^{1}$ При этом объем взятых кредитов увеличился лишь на $11 \%$. По подсчетам так называемого финансового омбудсмена П. А. Медведева, на 1 р. нового кредита у среднего заемщика сейчас приходится 1,8 р. по выплатам за старые долги ${ }^{2}$. Таким образом, можно сделать вывод, что в ближайшее время услуги так называемых «коллекторских агентств» будут пользоваться возрастающим спросом $[1$, c. $10-12 ; 2$, с. $162 ; 3$, с. 54$]$.

Одновременно, не смотря на появление Закона о потребительском кредитовании (займе), в котором введены нормы, ограничивающие круг действий лиц, осуществляющих деятельность по возврату задолженности, направленных на возврат задолженности по договору потребительского кредита (займа) [1, с. 17], деятельность коллекторов подвергается критике ввиду использования ими методов, которые можно классифицировать как запугивание, психологическое давление или злоупотребление правами $[4$, с. $7-9 ; 5$, с. 24]. Среди недавних примеров можно привести случай, когда коллекторское агентство ООО «Кредитэкспресс Финанс» рассылало должникам фиктивные повестки в суд и исковые заявления [6, с. 4]. Следовательно, необходимо дальнейшее развитие законодательства, регулирующее деятельность подобных агентств [7, с. 16; 8, с. 117], и было бы целесообразным обратится к зарубежному опыту борьбы со злоупотреблениями и использованием незаконных тактик взыскания денежных средств ${ }^{3}$.

Обычно в качестве примера удачного регулирования института коллекторской деятельности приводят деятельность США, в частности разработанный на федеральном уровне в 1977 г. Закон о добросовестной практике взыскания долгов (Fair Debt Collection Practices Act - FDCPA ${ }^{4}$ ) [1, c. 3; 9, с. 51-52]. При первичном анализе данного документа, являющегося одним из первых комплексных актов, всесторонне регулирующих коллекторскую деятельность и возникшим на базе многолетней судебной практики рассмотрения нарушений прав должников, может показаться, что он действительно максимально детально регулирует все этапы деятельности, направленной на возврат задолженности, и гарантирует защиту прав должника.

Так, в акте целенаправленно закреплено максимально широкое понятие «коллектор", под которым понимается «любое лицо, которое пользуется любым видом инструментов торговли между штатами, или почтовую корреспонденцию в предпринимательской деятельности, основной целью которой является возврат долгов, или лицо, которое на постоянной основе занимается возвратом долгов или попыт-

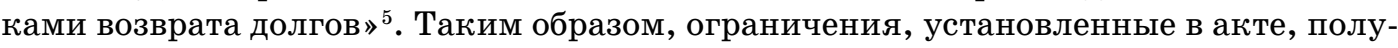
чают распространение на весь круг общественных отношений, связанных с возвратом долгов. Одновременно следует отметить, что действие акта распространяется только на задолженности физических лиц, возникшие из личных, семейных или домашних целей, при этом они не должны быть связаны с предпринимательской деятельностью должника.

1 Просроченные кредиты банков РФ. 2014-2015. URL : http://fd.ru/news/41419-ltahrefquotquotgtkak-izmenilsya-obem-prosrochennyh-kreditov-v-bankeltagt-s-kotorym-rabotaet-vasha-k.

${ }^{2}$ Заемщики ношу не тянут. URL : http://www.rg.ru/2014/11/20/kredit.html.

${ }^{3}$ Должников берут на испуг. URL : http://www.rg.ru/2014/11/11/kollektori.html.

${ }^{4}$ Fair Debt Collection Practices Act, as amended by Public Law 104-208, 110 Stat. 3009 (Sept. 30, 1996). URL : http://www.ftc.gov/enforcement/rules/rulemaking-regulatory-reform-proceedings/fairdebt-collection-practices-act-text.

${ }^{5} 15$ U.S. Code $\S 1692 \mathrm{a}$ - Definitions. URL : http://www.law.cornell.edu/uscode/text/15/1692a.

\section{Baikal Research Journal}


FDCPA прямо запрещает такое поведение коллекторов, которое может быть расценено в качестве запугивания или злоупотребления, а именно:

1. Запугивание - коллекторы не могут запугивать, притеснять или оскорблять должника или третьих лиц, с которыми они связываются. Например, они не имеют права:

- использовать угрозы применения насилия;

- публиковать списки имен должников (но они могут передавать эту информацию агентствам, ведущим кредитную историю);

- применять в общении с должником грубую или ненормативную лексику;

- звонить должникам, а также использовать автоинформаторы в период с 9 часов вечера до 8 часов утра;

- совершать частые назойливые звонки должникам - хотя в самом акте нет указания на количество звонков, в судебной практике выработан подход, согласно которому элементом запугивания является больше одного звонка в неделю, а серьезным злоупотреблением - более одного звонка в день, если должник отказывается разговаривать с коллектором и у коллектора нет законных оснований совершить дополнительный звонок, например, если кредитор получил судебное решение об обращении взыскания на доходы должника.

2. Ложные заявления. Коллекторы не имеют права сообщать недостоверную информацию, когда они пытаются взыскать задолженность. Например, они не могут:

- заявлять, что они работники прокуратуры или иные представители государства;

- сообщать, что должник совершает уголовное преступление;

- утверждать, что они представляют борю кредитных историй;

- демонстрировать неверную сумму задолженности;

- указывать, что предоставляемые документы являются юридически-значимыми;

- давать ложную информацию в бюро кредитных историй или иным третьим лицам.

Коллекторы также не имеют права заявлять, что они арестуют должника в случае неуплаты долгов; подадут иск в отношения должника, обратят взыскание, арестуют и продадут имущество или источники дохода, если они действительно не имеют право на это или у них нет такого намерения. Помимо этого, коллекторам запрещено разглашать информацию о наличии долга третьим лицам за следующим исключением: если он супруг/супруга должника, родитель должника, несовершеннолетний, представитель должника и др.

В качестве недобросовестной практики рассматриваются следующие попытки:

- взыскать дополнительные сборы, процент или другие выплаты помимо суммы задолженности за исключением случаев, когда изначальный договор или законодательство штата, в котором действуют коллекторы, позволяют это;

- изъять или угрожать изъятием собственности, если закон не позволяет это сделать;

- связываться с должником путем направления открыток;

- звонить после получения письменного заявления должника о продолжении взаимодействия с кредитором исключительно в письменной форме ${ }^{6}$.

Однако позволяет ли подобное подробное регулирование, подкрепленное десятилетиями судебной практики, эффективно пресекать злоупотребления со стороны коллекторских агентств, и какие у должников существуют методы для защиты своих прав?

615 U.S. Code $\S 1692 d$ - Harassment or abuse. URL : http://www.law.cornell.edu/uscode/ text/15/1692d.

\section{Baikal Research Journal}


На настоящий момент $14 \%$ американцев (около 30 млн чел.) имеют задолженности, что в среднем составляет около 1400 дол. на каждого должника7 ${ }^{7}$ При этом именно отрасль по взысканию долгов не первый год лидирует по количеству жалоб, поданных в федеральные органы.

Что могут сделать должники, страдающие, по их мнению, от незаконных тактик или злоупотребления?

Во-первых, что отличает законодательство США от российского законодательства в лучшую сторону, у должника есть право в письменном виде запретить коллектором связываться с должником в любых формах, кроме письменной. Любые звонки после получения данного письменного запроса признаются в качестве формы запугивания и свидетельства использования недобросовестных практик взыскания долгов и ведут к штрафам вплоть до 1000 дол.

Во-вторых, интересы должников защищают Федеральная торговая комиссия США (далее - ФТС) и Бюро финансовой защиты потребителей (БФЗП). Федеральная торговая комиссия за 2013 г. получила 204464 жалобы на действия коллекторов, из них 60485 в отношении коллекторских агентств ${ }^{8}$. Бюро финансовой защиты потребителей за 2013 г. приняло примерно 30300 жалоб ${ }^{9}$, в которых описываются следующие недобросовестные действия коллекторов:

- продолжающиеся попытки провести взыскание по несуществующим обязательствам - $34 \%$;

- использование противозаконных тактик общения с должником $-23 \%$;

- применение /угрозы применения незаконных действий - $14 \%$;

- раскрытие информации о задолженности - $13 \%$;

- ложные заявления или утверждения о своей принадлежности $-9 \%$;

- неправомерные виды связи или обмен информацией $-8 \%$.

В качестве показательного примера деятельности Федеральной торговой комиссии США можно привести случай с Техасским коллекторским агенством «Голдман Шварц», которое по соглашению с ФТС полностью прекратило свою коллекторскую деятельность и распродало все свои активы на общую сумму в 550000 дол. для выплаты возмещения потребителям, с которых взымались незаконные платежи. Агентство было закрыто по решению окружного суда в 2013 г. после того, как ФТС приняло решение по многочисленным жалобам на злоупотребления, в том числе неоднократные угрозы ареста и тюремного заключения на срок до трех лет, а также лишения пособия по инвалидности в отношении 67-летней женщины-инвалида при попытках коллекторов взыскать просроченную задолженность в 980 дол. $^{10}$

Еще одной проблемой акта является отсутствие регулирования использования технологий, которые возникли после 1977 г., таких как СМС-оповещение или использование социальных сетей $[10$, с. 376]. В настоящий момент коллекторы активно пользуются социальными сетями как для определения местонахождения должника и его имущества, так и для связи с должником. И если само по себе такое использование социальных сетей (например, звонок по номеру телефона, найденному на странице в Facebook) не противоречит закону, однако со стороны

${ }^{7}$ U.S. Fed. Trade Comm'n, The Structure and Practices of the Debt Buying Industry (2013) (FTC 2013 Debt Buyer Report). URL : http://www.ftc.gov/os/2013/01/debtbuyingreport.pdf.

${ }^{8}$ FTC announces top national consumer complaints for 2013. URL : http://www.ftc.gov/news-events/ press-releases/2014/02/ftc-announces-top-national-consumer-complaints-2013.

${ }^{9}$ Fair Debt Collection Practices Act, CFPB Annual Report 2014, March 20, 2014. URL : http://files. consumerfinance.gov/f/201403_cfpb_fair-debt-collection-practices-act.pdf.

${ }^{10}$ FTC Puts Texas-based Operation Permanently Out of the Debt Collection Business After It Allegedly Used Deception, Insults, and False Threats against Consumers. URL : http://www.ftc.gov/newsevents/press-releases $/ 2014 / 05 /$ ftc-puts-texas-based-operation-permanently-out-debt-collection?utm _ source $=$ govdelivery.

\section{Baikal Research Journal}


коллекторов встречаются многочисленные злоупотребления. Часты случаи, когда коллекторы создают фальшивые профили в социальных сетях обычно с фотографиями привлекательных девушек, после этого добавляются в друзья к должникам и начинают рассылать личные сообщения и оставлять комментарии на странице пользователя, тем самым нарушая запрет, установленный FDCPA на взаимодействие с третьими лицами. Судебная практика в подобных ситуациях выступает на стороне должника ${ }^{11}$.

Бюро финансовой защиты потребителей - достаточно молодой орган, созданный в 2011 г. и обладающий большими полномочиями в отношении коллекторских агентств, чем Федеральная торговая комиссия. Так, бюро имеет право осуществлять надзор за коллекторскими агентствами, издавать руководящие указания и разъяснения в отношении федерального законодательства, собирать информацию о жалобах в отношении коллекторских агентств, производить обучение коллекторов и выступать с законодательными инициативами в отношении деятельности по взысканию долгов ${ }^{12}$. Как ФТС, так и БФЗП имеют полномочия по расследованию и применению санкций в отношении коллекторских агентств, которые нарушают требования закона. Для того, чтобы их действия не дублировались, оба агентства находятся в постоянном взаимодействии и информируют друг друга перед началом производства в отношении коллектора ${ }^{13}$. Помимо этого должник может обратиться либо в офис генерального прокурора штата, либо в американскую ассоциацию коллекторов.

В судебном порядке должник, пострадавший от действий коллекторов, может получать компенсацию на сумму не более 1000 дол. плюс за реальные убытки. Однако, если прокуратурой подан иск в защиту неопределенного круга лиц, то может быть взыскана сумма вплоть до 500000 дол.

Таким образом, можно сделать вывод, что, не смотря на наличие достаточно подробного законодательства, регулирующего коллекторскую деятельности, и многолетнего опыта его применения, злоупотребления и прямые нарушения законодательства со стороны коллекторов являются основным источником жалоб граждан в области защиты прав потребителей $[11$, с. $55 ; 12$, с. 34]. При этом количество нарушений с каждым годом только растет. На наш взгляд, в первую очередь это связано с тем, что коллекторская деятельность является деятельностью коммерческой, а, следовательно, преследующая извлечение прибыли в качестве основной цели [9, с. 285]. При этом в США рынок коллекторских услуг с 2000 г. вырос в 6 раз, а крупные компании на этом рынке увеличили свою доходность на 300-500 \% ${ }^{14}$. Как показывает практика, ради сохранения подобной доходности коллекторские агентства охотно идут на различные злоупотребления и пользуются пробелами в законодательном регулировании, что в конечном итоге приводит к серьезному нарушению прав, в частности, наименее защищенных слоев общества.

\footnotetext{
${ }^{11}$ Melanie Beacham vs. MarkOne Financial, LLC, In the Circuit Court of Sixth Judicial Circuit In and For Pinellas County, State of Florida, Civil Division, Case No 10-12883CI-15.

${ }^{12}$ Dodd-Frank Wall Street Reform and Consumer Protection Act («Dodd-Frank Act»»), Pub. L. 11-203, $\S 1089$, 124 Stat. 1376, 2092-93 (2010) (amending the Fair Debt Collection Practices Act, 15 U.S.C. $\S 1692$ et seq.).

${ }^{13}$ Memorandum of Understanding Between the Consumer Financial Protection Bureau and the Federal Trade Commission (Jan. 2012). URL : http://www.ftc.gov/sites/default/files/attachments/press-releases/federaltrade-commission-consumer-financial-protection-bureau-pledge-work-together-protect-consumers/120123ftccfpb-mou.pdf.

${ }^{14}$ Federal Trade Commission (FTC). 2013. The structure and practices of the debt buying industry. URL : http://www.ftc.gov/os/2013/01/debtbuyingreport.pdf.
}

\section{Baikal Research Journal}




\section{Список использованной литературы}

1. Порошкина Ю. О. Законодательное закрепление запретов и ограничений в коллекторской деятельности / Ю. О. Порошкина / / Законы России: опыт, анализ, практика. — 2014. № 8. - C. 17-22.

2. Цепкова Т. М. Некоторые вопросы исполнительного производства российского и зарубежного законодательства / Т. М. Цепкова. С. А. Филиппов // Вестник Саратовской государственной юридической академии. — 2014. — № 2 (97). — С. 159-164.

3. Мирошниченко А. А. Средства принуждения должника к исполнению судебных актов (сравнительно-правовой обзор) / А. А. Мирошниченко // Арбитражный и гражданский процесс. - 2013. - № 3. - С. 51-56.

4. Астапова Т. Ю. О подходах к определению понятия «коллекторская деятельность» / Т. Ю. Астапова // Законы России: опыт, анализ, практика. - 2014. — № 8. - С. 7-11.

5. Гуреев В. А. Реальное и мнимое значение коллекторской деятельности в механизме исполнения актов юрисдикционных органов в российской федерации / В. А. Гуреев // Законы России: опыт, анализ, практика. - 2014. - № 8. - С. 23-25.

6. Парфенчиков А. О. Отдельные аспекты нормативного регулирования коллекторской деятельности в Российской Федерации / А. О. Парфенчиков // Законы России: опыт, анализ, практика. - 2014. - № 8. - С. 3-7.

7. Илюшина М. Н. Новеллы законодательства о потребительском кредитовании и гражданско-правовой механизм профессиональной деятельности коллекторских агентств / М. Н. Илюшина // Законы России: опыт, анализ, практика. - 2014. № 8. - C. 11-17.

8. Пластинина Н. Н. Комментарий на новость про коллекторов / Н. Н. Пластинина // Административное право. - 2015. — № 4. - С. 117-119.

9. Некрасов С. Ю. Проблемы реформирования административного судопроизводства / С. Ю. Некрасов // Итоги и перспективы развития судебной реформы в Российской Федерации : материалы Всерос. науч.-практ. конф. - Иркутск, 2012. - С. 282-286.

10. Эффективность принудительного исполнения судебных решений и актов других органов : сб. материалов Междунар. науч.-практ. конф. Казань, 8-11 июня 2011 г. / З. М. Али-Заде, Ю. А. Артемьева, Й. Аутдехааг [и др.] ; отв. ред. А. О. Парфенчиков, Д. Х. Валеев. - М. : Статут, 2011. - 430 с.

11. Выскуб В. С. История становления института судебных приставов (сравнительно-правовой анализ) / В. С. Выскуб // История государства и права. - 2013. — № 22. - С. 53-57.

12. Пыхтин С. В. Принципы добросовестной практики деятельности коллекторских агентств в Великобритании / С. В. Пыхтин // Международное публичное и частное право. 2015. — № 3. - С. 33-36.

\section{References}

1. Poroshkina Yu. O. Legal Prohibitions and Restrictions in Regulating Collectors' Activity. Zakony Rossii: opyt, analiz, praktika = Law of Russia: Experience, Analysis, Practice, 2014, no. 8, pp. 17-22. (In Russian).

2. Tsepkova T. M., Filippov S. A. Some Issues on Enforcement of Russian and Foreign Legislations. Vestnik Saratovskoi gosudarstvennoi yuridicheskoi akademii = Saratov State Law Academy Bulletin, 2014, no. 2 (97), pp. 159-164. (In Russian).

3. Miroshnichenko A. A. Methods of enforcing debtors to execute judicial acts (a comparative and legal review). Arbitrazhnyi $i$ grazhdanskii protsess = Arbitral and Civil Procedure, 2013, no. 3, pp. 51-56. (In Russian).

4. Astapova T. Yu. Approaches to the Definition of Debt Collection Activity. Zakony Rossii: opyt, analiz, praktika $=$ Law of Russia: Experience, Analysis, Practice, 2014, no. 8, pp. 7-11. (In Russian).

5. Gureev V. A. Real and Fictional Importance of Collectors' Activity in the Mechanism of Executing Jurisdictional Authorities' Acts of the Russian Federation. Zakony Rossii: opyt, analiz, praktika = Law of Russia: Experience, Analysis, Practice, 2014, no. 8, pp. 23-25. (In Russian).

6. Parfenchikov A. O. Prospects of Collectors' Activity Development in Russia. Zakony Ros sii: opyt, analiz, praktika = Law of Russia: Experience, Analysis, Practice, 2014, no. 8, pp. 3-7. (In Russian).

\section{Baikal Research Journal}


7. Ilyushina M. N. Legislation Novels on Consumer Lending and the Civil Law Mechanism of Professional Activity of Collectors' Agencies. Zakony Rossii: opyt, analiz, praktika = Law of Russia: Experience, Analysis, Practice, 2014, no. 8, pp. 11-17. (In Russian).

8. Plastinina N. N. Comments on the news about collectors. Administrativnoe pravo $=$ Administrative Law, 2015, no. 4, pp. 117-119. (In Russian).

9. Nekrasov S. Yu. Problems of reforming administrative procedure. Itogi i perspektivy raz vitiya sudebnoi reformy $v$ Rossiiskoi Federatsii. Materialy Vserossiiskoi nauchno-prakticheskoi konferentsii [Result and prospects of developing the judicial reform in the Russian Federation. Materials of All-Russian Research Conference]. Irkutsk, 2012, pp. 282-286. (In Russian).

10. Ali-Zade Z. M., Artemyeva Yu. A., Autdekhaag I. et al.; Parfenchikov A. O., Valeev D. Kh. (eds). Effektivnost' prinuditel'nogo ispolneniya sudebnykh reshenii i aktov drugikh organov. Materialy Mezhdunarodnoi nauchno-prakticheskoi konferentsii. Kazan', 8-11 iyunya 2011 g. [Efficiency of compulsory execution of legal judgements and acts of other bodies. Materials of International Research Conference. Kazan, June 8-11, 2011,]. Moscow, Statut Publ., 2011. 430 p.

11. Vyskub V.S. History of formation of the court marshal institution (comparative and legal analysis). Istoriya gosudarstva $i$ prava $=$ History of State and Law, 2013, no. 22, pp. 53-57. (In Russian).

12. Pykhtin S. V. Principles of fair practice of activities of collection agencies in Great Britain. Mezhdunarodnoe publichnoe i chastnoe pravo = Public and Private International Law, 2015, no. 3, pp. 33-36. (In Russian).

\section{Информация об авторе}

Зеничев Николай Андреевич - аспирант, кафедра организации службы судебных приставов и исполнительного производства, Российская правовая академия Министерства юстиции Российской Федерации, 117638, г. Москва, ул. Азовская, 2, e-mail: nzenichev@gmail.com.

\section{Author}

Nikilay A. Zenichev - PhD Student, Chair of Management Organization for Bailiff Service and Enforcement Proceedings, Russian Law Academy of the Ministry of Justice of the Russian Federation, 2 Azovskaya St., 117638, Moscow, Russian Federation; e-mail: nzenichev@gmail.com.

\section{Библиографическое описание статьи}

Зеничев Н. А. Использование незаконных тактик взыскания денежных средств коллекторскими агентствами и методы борьбы с ними в странах англо-саксонской правовой семьи / Н. А. Зеничев // Baikal Research Journal. — 2016. — T. 7, № 1. — DOI : 10.17150/2411$\underline{6262.2016 .7(1) .19}$.

\section{Reference to article}

Zenichev N. A. Use of illegal tactics of collecting monetary items by collection agencies and methods of combatting them in the countries of Anglo-Saxon legal families. Baikal Research Journal, 2016, vol. 7, no. 1. DOI: 10.17150/2411-6262.2016.7(1).19. (In Russian).

\section{Baikal Research Journal}

